\section{The Nature of the Virus Principle in Mosaic Disease.}

DURING the course of investigations designed to determine the nature of the infective principle present in the virus of tomato mosaic, a bacterial growth showing various forms was isolated. Stained smears prepared from this showed so many bacteria in a state of breakdown that the phenomenon seemed worth examining further.

The original isolations were prepared as follows. Pieces of tomato stem taken from plants showing symptoms of mosiac disease and 'stripe' disease, were sterilised on the outside with calcium hypochlorite, and inserted into tubes of potato agar. No the filtrates from $L 3$ and $L 5$ filters were added. Poured plates confirmed this observation.

Potato broth tubes to which $L 3$ filtrate of healthy tomato juice was added remained turbid, and neither decrease in the number of bacteria present nor change of form have been observed. The action of the virus seems limited to certain organisms, for when added to mixed broth cultures prepared from soil and horse manure, no obvious clearing or browning resulted.

In view of these results, which have been repeatedly obtained, it is suggested that the principle causing mosaic disease of the tomato is of the bacteriophage type, which, in the first place, enters the plant with the organism it parasitises in Nature and, becoming adapted to life within the tissues of the tomato plant,

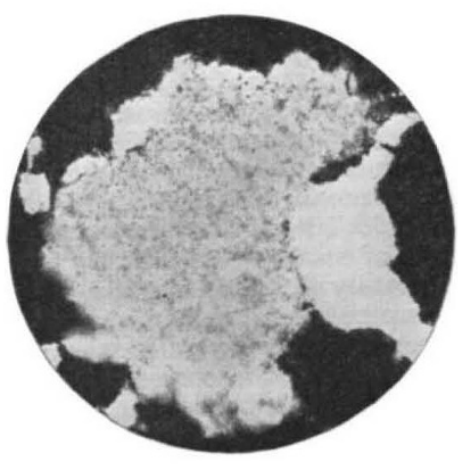

(PIG. 1.

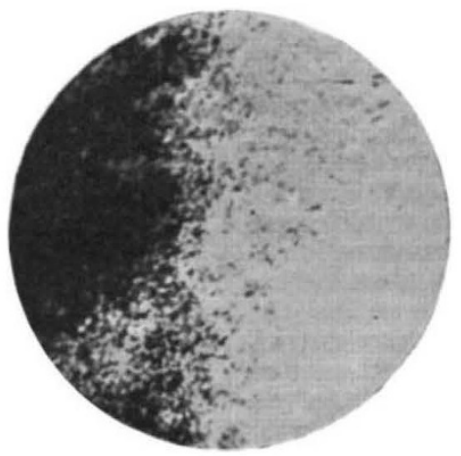

FIG. 2.

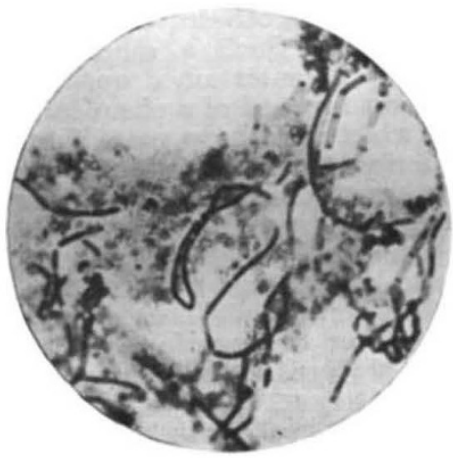

FIG. 3. growth resulted for ten weeks; but in the twelfth week three tubes showed a grey-brown bacterial growth on the agar round the piece of tomato tissue.

Stained smears showed small clear areas (Fig. 1) at a magnification of 150 . (In the reproduction, all the illustrations have been reduced to two-thirds of their original size.) When examined at a magnification of 1250 these areas appeared as in Fig. 2. The bacterial cells had been destroyed, leaving a granular deposit with deeply staining fragments strongly resembling minute organisms. At other portions of the smears (Fig. 3), certain cells were seen to be much swollen and speckled with minute darkly staining granules. Cultures of the original growth were emulsified with water and filtered through a sterile Chamberland $L 3$ filter. When added to a broth culture of the original growth which had been freed so far as possible from "phage', some slight clearing and diminution of the number of bacteria resulted.

In view of the conditions under which the original isolations were obtained, it seemed possible that the bacteriophage principle present in the cultures might be the active virus of mosaic disease present in the tomato tissue from which the isolations were prepared.

Consequently, a quantity of virus was extracted from a tomato plant originally inoculated with the virus of $A u c u b a$ mosaic disease, but which, since inoculation, had also developed symptoms of 'stripe' disease. Portions of the virus which had passed through $L 3, L 5$, and $L 7$ filters under aseptic conditions were tubed separately. These were added in 1 c.c. lots to turbid potato broth cultures of the original growth which had been freed so far as possible from 'phage'. In 24 hours, the tubes receiving filtrates from the $L 3$ and $L 5$ filters showed slight clearing; and in 48 hours, there was definite clearing of these tubes, and in some cases very slight clearing and browning where the filtrate from an $L 7$ filter had been added. Microscopic examination of drops from the cultures showed an appreciable diminution of bacterial numbers accompanied by apparent fragmentation when causes the symptoms now associated with mosaic disease.

If this view be correct, its implications in the study of virus diseases are considerable.

Experimental and Research Station, W. F. Bewley. Cheshunt, Herts, Mar. 5.

\section{Hardening of Moti, a Japanese Rice Food-stuff.}

IN the course of my researches on the mechanism of the setting and hardening of cement, and on account of the similarity of the problems involved, I have investigated also the problem of the hardening of moti, a Japanese rice food-stuff. Glutinous rice, previously steamed with special apparatus, is made into moti by pounding. In the air, it hardens into a stone-like mass. The results I have obtained so far are as follows :

(1) The hardening phenomenon occurs in two ways : (a) It may be due to desiccation, that is, the water in the moti goes off into the air, the result being the formation of a stone-like mass; or $(b)$ it may be due to internal changes. For example, when freshly prepared soft moti is preserved under paraffin, although desiccation is thus prevented, the moti hardens, but to a somewhat soft mass. This mass hardens further on exposure to the air, cracking and forming a stone-like mass.

(2) By differential thermal analysis in a specially designed vessel, during both cooling and heating, moti shows at $63.5^{\circ} \mathrm{C}$. a transition point. This change is reversible. The transition point does not appear with freshly prepared moti, but it appears with moti which has been cooled once in a hermetically sealed vessel.

(3) J. R. Katz (Zeit. physik. Chem., A, 150, 37 ; 1930 , etc.) suggested a transition point at about $60^{\circ} \mathrm{C}$. in the staling process of bread, and thinks the existence of this point is the cause of bread becoming stale. So far as moti is concerned, this does not

No. 3203 , VoL. 127] 